\title{
Effect of different delivery modes on the short-term strength of the pelvic floor muscle in Chinese primipara
}

\author{
Yun Zhao' ${ }^{1}$ Li Zou², Mei Xiao ${ }^{1 *}$, Wan Tang ${ }^{1}$, Hai-yi $\mathrm{Niu}^{3}$ and Fu-yuan Qiao ${ }^{3}$
}

\begin{abstract}
Background: To investigate the effect of different delivery modes and related obstetric factors on the short-term strength of the pelvic floor muscle after delivery in Chinese primipara.

Methods: A total of 4769 healthy Chinese primiparas at postpartum 6-8 weeks were interviewed. According to the difference of delivery mode, the selected primiparas were divided into 2 groups, including cesarean delivery group containing 2020 and vaginal delivery group containing 2749. All the vaginal deliveries were further divided into 3 groups, including episiotomy group containing 2279, perineal laceration group containing 398, and forceps assisted group containing72. The scales of their pelvic floor muscle (PFM) strengths were examined by specially trained personnel using digital palpation (Modified Oxford scale:0-5 grade). According to participants' willingness, if the PFM strength was weak ( 0 or 1 grade), at-home PFM training would be recommended and an electrical stimulation combined with biofeedback therapy would be conducted for them in hospital. Twelve weeks after delivery, the PFM strength would be measured again. For statistical analysis, $t$-test, one-way variance analysis, Chi-square analysis, Kruskal-Wallis test $\mathrm{H}$, Mann-Whitney $U$ test and Wilcoxon test were carried out.
\end{abstract}

Results: The PFM strength in cesarean delivery group was higher than in vaginal delivery group $(p<0.05)$. Among 3 vaginal delivery groups, the PFM strength in perineal laceration group was the highest $(p<0.05)$; however, there was no difference in PFM strength between episiotomy group and forceps assisted group $(p>0.05)$. After accepting PFM training at home and therapy in hospital, 305 women showed increased PFM strength $(p<0.05)$.

Conclusions: Vaginal delivery is an independent risk factor causing the damage of PFM, and episiotomy may cause injury of PFM. Through PFM training at home and therapy in hospital, those damage will resume as soon as possible in the short-time period after delivery.

Keywords: Pelvic floor muscle strength, Cesarean delivery, Episiotomy, Perineal laceration, Forceps, Eletrical stimulation, Biofeedback

\section{Background}

Pelvic floor disorders (PFDs) are common and prevalent in adult women, which negatively affect women's self-perception of their body image and life quality [1] and bring great economic burden to patients and society. PFDs has become a public health problem attracting worldwide attention. According to recent epidemiological studies, pregnancy and childbirth are two independent

* Correspondence: xiaomei971203@163.com

${ }^{1}$ Department of Obstetrics, Maternal and Child Health Hospital of Hubei

Province, No 745 Wuluo Road, Wuhan City, People's Republic of China

Full list of author information is available at the end of the article factors causing PFDs [2]. Can cesarean delivery really protect pelvic floor function of women? Some studies have shown that the selective cesarean delivery may have a protective effect for the pelvic floor, but others have shown that the protective effect is very limited in the long term postpartum period [3]. How do different delivery modes affect female Pelvic Floor Muscle(PFM) and what are the effects of these delivery modes on Chinese primiparas in the short-term postpartum? This study was conducted to estimate the effect of different delivery modes on the PFM strength at postpartum 6-8 weeks and the refection of PFM training on the weak PFM strength in the short-time

(c) The Author(s). 2018 Open Access This article is distributed under the terms of the Creative Commons Attribution 4.0 International License (http://creativecommons.org/licenses/by/4.0/), which permits unrestricted use, distribution, and 
period after delivery. The scale of PFM strength was examined by specially trained personnel using digital palpation.

\section{Methods \\ Ethical approval}

The study protocol was approved by the Ethics Committee of Maternal and Child Health Hospital of Hubei Province(201301) and all included women signed written informed consent.

\section{Selection of patients and study design}

Women who had delivered in the obstetric department at the Maternal and Child Health Hospital of Hubei Province from January 2013 to January 2014 and visited pelvic floor rehabilitation department in postpartum 6-8 weeks period were selected as research objects. All selected women were healthy Chinese primiparas, with age ranging from 20 to 35 years old. They had clean lochia without obstetric complications. Exclusion criteria included those with age less than 20 years old or more than 35 years old, non-Chinese nationality, multiple pregnancies, vaginitis and urinary tract infection, and mental incapacity. A total of 4959 women were selected in this study, excluding 39 for being non-Chinese nationality, 105 for having red lochia, 46 for not cooperative with specially trained personnel. According to delivery mode, 4769 cases were divided into 2 groups, including cesarean delivery group containing 2020 and vaginal delivery group containing 2749. Then, All vaginal deliveries were further divided into 3 groups, including episiotomy group containing 2279 (Left lateral episiotomy during vaginal delivery), perineal laceration group containing 398 (I, II degree natural perineal laceration during vaginal delivery), and forceps assisted group containing 72 (Left lateral episiotomy and forceps assisted operation during vaginal delivery). In our hospital, all instrument-assisted operations of vaginal delivery were carried out with the aid of forceps in place of vacuum-assisted delivery, and midwifery care was conducted during the antenatal period, labor and delivery period, and postnatal period according to The National Midwifery Guidelines. The evaluation of pelvic floor muscle strength and routine physical examination on maternal gynecological situation were performed by trained specialists. All the investigation and examination results were recorded truthfully, including patient characteristics, medical history, and pregnancy delivery data. All selected women had not accepted formal training of pelvic floor muscle during pregnancy and postpartum 6-8 weeks period (see Fig. 1).

According to participants' actual condition in the 6-8 postpartum weeks, if the PFM strength was weak ( 0 or 1 grade according to modified Oxford scale), at-home PFM training plus in-hospital electrical stimulation combined with biofeedback therapy would be recommended for them, that was guided by specialized medical personnel in our department. Twelve weeks after delivery, the PFM strength would be examined again. There were only 310 primiparas with weak PFM strength who were treated with at-home PFM training plus in-hospital electrical stimulation combined with biofeedback therapy. Among them, excluding 1 case having electrostatic proble phobia when accepting electrical stimulation for the first time, 3 cases showing irregular vaginal bleeding, 1 case failing to continue treatment, the remaining 305 cases were included in the study for observing the therapeutic effect of PFM training at home plus PFM therapy in hospital.

\section{Determination of pelvic floor muscle strength}

Pelvic floor muscle was determined by specialized medical personnel using digital palpation. Before the examination, women were told to empty the bladder and take lithotomy position. PFM contraction without any movement of the pelvis or visible contraction of the glutei, hip, or abdominal muscles was emphasized [4].

Digital palpation [5]. First put the index and middle fingers $2-3 \mathrm{~cm}$ deep into the vagina and identify the levator ani muscle. Then, separate the two fingers and fall on two sides of levator ani muscle, meanwhile, put the other hand on the abdomen to make sure the abdominal muscle was relaxed. The scale of pelvic floor muscle strength was described by Modified Oxford scale. On the basis of contraction strength and retraction capability, the PFM strength was divided into $0-5$ grades and 6 classes. (Table 1 ).

\section{PFM training [6]}

When the scale of PFM during 6-8 weeks postpartum period was $<2$ grades ( 0 or 1 grade), the specialists in our department of pelvic floor rehabilitation would teach them how to contract their PFM by demonstrating vaginal palpation. At first, the specialist placed her index finger into the vaginal and told the women to lift and squeeze around the finger. Then, the women took Kegel exercise 10 times a day at home, each exercise included 10 repetitions. After 12 weeks of postpartum, the woman was told to come back again for PFM strength examination.

\section{Eletrical stimulation and biofeedback [7]}

The PFM enforcement program consisting of biofeedback and electrical stimulation therapy, lasting $30 \mathrm{~min}$, was implemented twice a week. A complete course of PFM enforcement program lasts for 5 weeks, which is 10 times as long as the program of biofeedback and electrical stimulation. MyoTrac infiniti (SA9800) device (Thought Technology Inc., Montreal, Canada) was adopted in this experiment. The biostimulation feedback system is based on biofeedback technology, bioformatics principles and bioengineering technology, and so on. Safe and effective electrical stimulation combined with biofeedback technology were conducted by vaginal sensor to record pelvic 


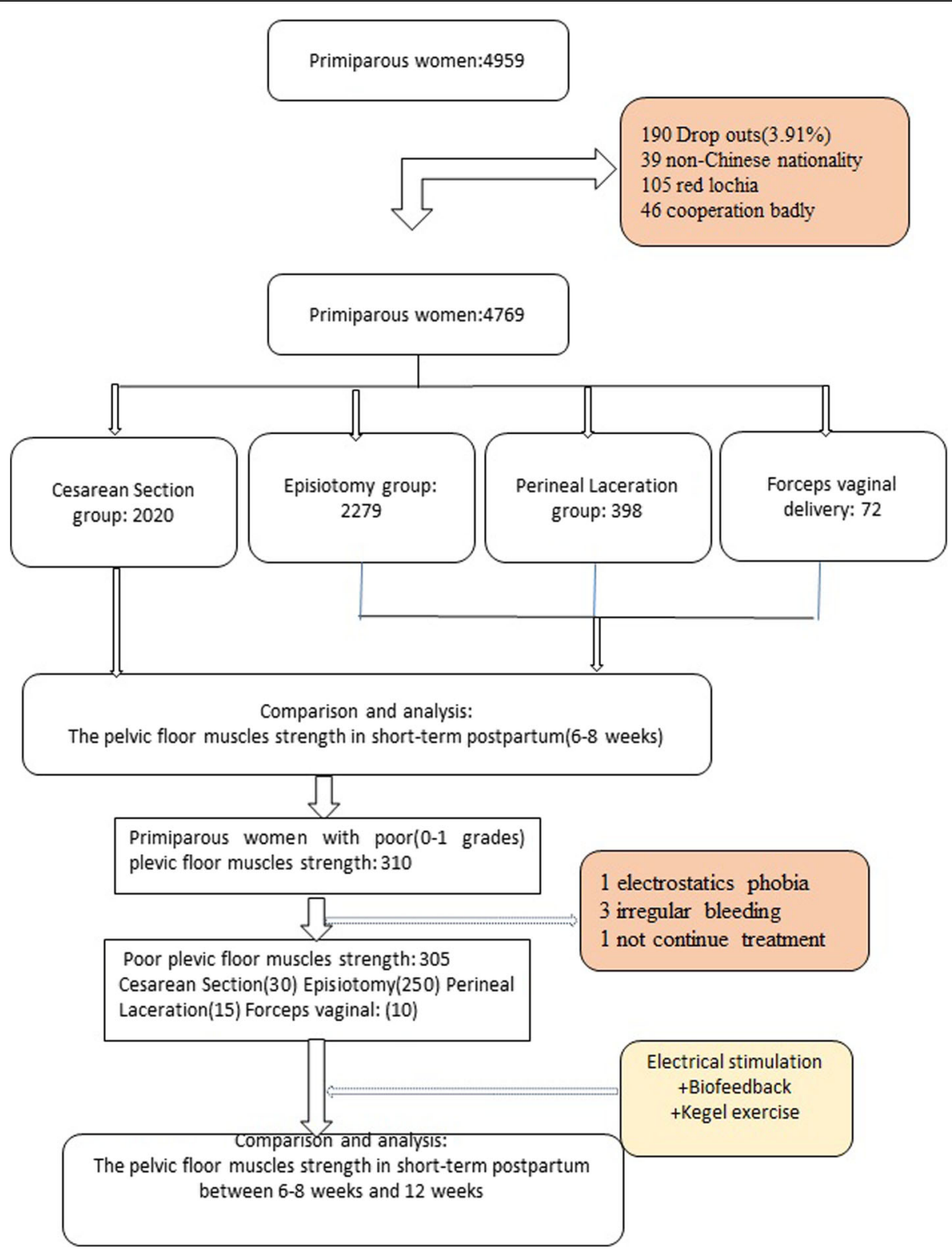

Fig. 1 Flowchart demonstrating. The number of Participants who attended and the reasons for lost to follow-up

Table 1 Modified Oxford scale for digital evaluation of pelvic floor muscle strength

\begin{tabular}{ll}
\hline Grade & Description \\
\hline 0 & Nil \\
1 & Flicker \\
2 & Weak \\
3 & Moderate, slight lift of the examiner's fingers, \\
& no resistance \\
4 & $\begin{array}{l}\text { Good, sufficient to elevate the examiner's } \\
\text { fingers against light resistance } \\
5\end{array}$ \\
& $\begin{array}{l}\text { Strong, sufficient to elevate the examiner's } \\
\text { fingers' against strong resistance }\end{array}$ \\
\hline
\end{tabular}

floor muscle activity and pelvic floor muscle contraction strength, based on which the strength of electrostimulation was controlled. The direct vagina low-voltage low-frequency electric stimulation including 3 reference electrodes on the iliac and two sides hypogastric skin was performed to prevent the abdominal or giuteus musles contraction. A separate proble was used for primiparas to prevent cross-infection. With the help of computer graphics, various parameters of the device was adjusted to make every primipara feel the PFM active and passive contraction and guarantee the primiparas not feel any pain or discomfort. The parameters of electrical stimulation were set as pulse width of 20-40 us and low voltage of $40-80 \mathrm{~Hz}$. The electrostimulation included 
rapid contraction exercise of PFM (stimulation and interval time is $2 \mathrm{~s}: 2 \mathrm{~s}$ ) and continuous contraction exercise of PFM ((stimulation and interval time is $5-8 \mathrm{~s}: 10 \mathrm{~s})$. The electrical stimulation and biostimulation feedback therapies were applied alternatively based on the needs of primiparas with weak PFM strength. Each treatment of electrical stimulation combined with biostimulation lasted for $30 \mathrm{~min}$, and was conducted two times per week, 10 times for a complete course of treatment.

\section{Statistical analyses}

All the statistical analyses were carried out using the Statistical Package of Social Sciences software (SPSS Version 13.0 Inc., Chicago, IL, USA). The values and variables were reported in the form of mean \pm standard deviation. One-Way ANOVA and Student's test were performed to compare the variables in Gaussian distribution. Chi-square test was used to evaluate the categorical variables. Kruskal-Wallis $\mathrm{H}$ test was used to assess the difference of the PFM function and the variables in no Gaussian distribution among $\mathrm{K}$ independent samples. Mann-Whitney $U$ test and Bonferroni's correction were conducted to assess further pairwise samples. Wilcoxon test was used to evaluate the difference of the PFM function before and after PFM training. The difference was considered statistically significant at $p<0.05$.

\section{Results}

\section{Demographic data of cesarean delivery group and} vaginal delivery group

Through statistical comparison, it can be known that the difference is not statistically significant between cesarean delivery group and vaginal delivery group $(p>0.05)$. Samples in cesarean delivery group have older age, heavier new baby's weight, and higher rate of gestational diabetes mellitus(GDM) than that in vaginal delivery group $(p<0.05)$. The demographic data of two groups are list in Table 2.

The PFM strength of women in postpartum 6-8 weeks after accepting cesarean delivery or vaginal delivery Table 3 shows that the PFM strength of women in cesarean delivery group is stronger than in vaginal delivery group, and the difference is statistically significant $(p<0.05)$.

\section{Demographic data of the three groups of vaginal delivery} Through statistical comparison, it can be known that there are no differences in age, BMI of delivery, new baby's birth weight, gestational weight gain, gestational age at birth and the rate of GDM among episiotomy group, perineal laceration group, and forceps assisted group $(p>0.05)$. The median duration of the 2nd stage in forceps assisted group was $28 \mathrm{~m}(95 \% \mathrm{CI}, 11-129 \mathrm{~m})$, there was no statistical significance among the three groups $(p>0.05)$. The rates of 0,1 and 2 degree of perineal lesions in perineal laceration group was $1.3,26.4 \%(105 / 398)$ and $72.4 \%(288 / 398)$. The rates of 2 degree of perineal lesions in episiotomy group and in forceps assisted group were $100 \%$, there was no 3 or 4 degree of perineal lesions in any of the three groups of vaginal delivery. There was common preineum local block anesthesia before episiotomy but no neuraxial labor anlagesia for vaginal delivery. The demographic data of 3 vaginal delivery groups are list in Table 2.

\section{The PFM strength of women in postpartum 6-8 weeks among three groups of vaginal delivery}

Table 4 shows that the PFM strength of women among three vaginal delivery groups is significant different $(p<0.05)$. The PFM strength in perineal laceration group is stronger than

Table 2 Comparison of demographic data among Cesarean delivery and three groups of vaginal delivery

\begin{tabular}{|c|c|c|c|c|c|c|c|c|c|}
\hline & $\begin{array}{l}\text { Cesarean } \\
\text { delivery } \\
\text { Group } \\
(2020)\end{array}$ & $\begin{array}{l}\text { Vaginal } \\
\text { delivery } \\
\text { Group } \\
\text { (2749) }\end{array}$ & $\operatorname{tor} X^{2}$ & $p$ value & $\begin{array}{l}\text { Perineal } \\
\text { laceration } \\
\text { Group } \\
(398)\end{array}$ & $\begin{array}{l}\text { Episiotomy } \\
\text { Group }\end{array}$ & $\begin{array}{l}\text { Forceps } \\
\text { assisted } \\
\text { Group } \\
(72)\end{array}$ & $\begin{array}{l}\text { F or } \\
X^{2}\end{array}$ & $p$ value \\
\hline Age(y) [mean \pm sd] & $28.3 \pm 3.0$ & $27.7 \pm 2.9$ & 7.017 & 0.000 & $27.7 \pm 2.8$ & $27.7 \pm 2.9$ & $28.1 \pm 2.8$ & 0.639 & 0.528 \\
\hline $\begin{array}{l}\text { BMI of delivery } \\
\left(\mathrm{kg} / \mathrm{m}^{2}\right)[\text { mean } \pm \mathrm{sd}]\end{array}$ & $27.3 \pm 2.6$ & $27.5 \pm 2.7$ & -1.658 & 0.098 & $27.5 \pm 2.8$ & $27.4 \pm 2.7$ & $27.8 \pm 2.6$ & 0.656 & 0.519 \\
\hline $\begin{array}{l}\text { Birth weight }(\mathrm{g}) \\
{[\text { mean } \pm \mathrm{sd}]}\end{array}$ & $3322.0 \pm 550.0$ & $3252.6 \pm 476.1$ & 4.554 & 0.000 & $\begin{array}{l}3226.3 \pm \\
334.2\end{array}$ & $3254.8 \pm 499.1$ & $\begin{array}{l}3329.2 \pm \\
385.0\end{array}$ & 1.563 & 0.210 \\
\hline $\begin{array}{l}\text { Gestational weight gain }(\mathrm{kg}) \text { [mean } \\
\pm \mathrm{sd}]\end{array}$ & $15.9 \pm 7.0$ & $15.6 \pm 7.2$ & 1.470 & 0.142 & $15.6 \pm 6.7$ & $15.6 \pm 7.3$ & $14.6 \pm 6.2$ & 0.639 & 0.528 \\
\hline $\begin{array}{l}\text { Gestational age at } \\
\text { birth(w) }[\text { mean } \pm \text { sd] }\end{array}$ & $39.2 \pm 1.4$ & $39.3 \pm 1.4$ & -0.638 & 0.523 & $39.2 \pm 1.3$ & $39.3 \pm 1.4$ & $39.7 \pm 1.1$ & 2.135 & 0.094 \\
\hline Rate of GDM (\%) & $30.0(605 / 2020)$ & $26.0(714 / 2749)$ & 9.009 & 0.003 & $\begin{array}{l}24.1(96 / \\
398)\end{array}$ & $26.0(593 / 2279)$ & $25(18 / 72)$ & 0.660 & 0.719 \\
\hline $\begin{array}{l}\text { Duration of } 2 \text { nd } \\
\operatorname{sta}(\mathrm{m})[\text { median }(95 \% \mathrm{Cl})]\end{array}$ & / & $26(7-110)$ & / & / & $29(6-77)$ & 25(7112) & 28(11-129) & 4.258 & 0.119 \\
\hline
\end{tabular}

Student's test, One-Way ANOVA, Kruskal-Wallis $\mathrm{H}$ test and Chi-square analysis are performed; GDM: gestational diabetes mellitus 
Table 3 The PFM strength of women in 6-8 weeks postpartum betwee the two delivery modes

\begin{tabular}{llllllll}
\hline & $N$ & 0 & 1 & 2 & 3 & 4 & 5 \\
\hline Cesarean secarean Group & 2020 & 38 & 232 & 1364 & 366 & 20 & 0 \\
Vaginal delivery Group & 2749 & 223 & 1184 & 1195 & 140 & 7 & 0 \\
$Z$ & -27.861 & & & & & \\
$p$ value & 0.000 & & & & & & \\
\hline
\end{tabular}

Mann-whitney $U$ test is performed

that in episiotomy group and forceps vaginal delivery group, and the intergroup differences are statistically significant $(p<$ 0.025). There is no significant difference in PFM strength of women between episiotomy group and forceps vaginal delivery group $(p>0.05)$.

\section{The weak PFM strength of women in postpartum 6- 8 weeks}

There were 305 cases with weak PFM willing to receive at-home PFM exercise plus electrical stimulation combined with biofeedback therapy in hospital twice a week (10 times for a complete course). Among them, there were 30 cases of cesarean delivery, 250 cases of were episiotomy, 15 cases of perineal laceration, and 10 cases of forceps vaginal delivery. By the last time of their treatment (nearly 12 weeks postpartum), their PFM strengths were examined again, and it could be found that their PFM strengths were improved $(p<0.05)$, as shown in Table 5.

\section{Discussion}

Pregnancy and childbirth are two important events in a women's life. The two phases of life have been proved to be associated with increased incidence of PFDs. Pregnancy and childbirth, especially vaginal childbirth, are two independent factors causing PFDs $[8,9]$. Although severe morbidity of women from PFDs is rare, PFDs do seriously affect the quality of women's life. At present China, permanent damage of PFM in older women has attracted much attention and lots of money have been invested on this issue. However, the prevention and treatment of PFDs

Table 4 The PFM strength of women in 6-8 weeks postpartum among the different vaginal delivery modes

\begin{tabular}{|c|c|c|c|c|c|c|}
\hline & $\mathrm{N}$ & 0 & 1 & 2 & 3 & 4 \\
\hline Perineal laceration Group(1) & 398 & 21 & 151 & 192 & 30 & 4 \\
\hline Episiotomy Group(2) & 2279 & 197 & 996 & 975 & 108 & 3 \\
\hline \multirow[t]{2}{*}{ Forceps assisted Group(3) } & 72 & 5 & 37 & 28 & 2 & 0 \\
\hline & \multicolumn{2}{|c|}{ (1)(2) } & (1)-(2) & \multicolumn{2}{|l|}{ (1)-(3) } & (2)-(3) \\
\hline$x^{2}$ or $Z$ & \multicolumn{2}{|l|}{18.736} & -4.182 & \multicolumn{2}{|c|}{-2.550} & -0.830 \\
\hline$p$-value & \multicolumn{2}{|l|}{0.000} & 0.000 & \multicolumn{2}{|l|}{0.032} & 1.000 \\
\hline
\end{tabular}

Table 5 Comparison with the PFM strength before and after treatment

\begin{tabular}{llllllll}
\hline & $\mathrm{n}$ & 0 & 1 & 2 & 3 & 4 & 5 \\
\hline Before & 305 & 208 & 97 & 0 & 0 & 0 & 0 \\
After & 305 & 0 & 51 & 202 & 40 & 12 & 0 \\
$Z$ & & -15.572 & & & & & \\
$p$-value & & 0.000 & & & & & \\
\hline
\end{tabular}

Wilcoxon test is used

during pregnancy and childbirth have not been attached with sufficient attention. The postpartum period is the time during which the PFM damage of women may develop into the most serious condition (fortunately it is reversible). If a woman in postpartum cannot persist on accepting conservation treatment (pelvic muscle exercise, electrical stimulation, and biofeedback, and so on) for postnatal PFDs, permanent PFDs will gradually come into being $[10,11]$. Paying attention to PFM damage and PFDs in recent postpartum period as well as finding effective method to guide restoration of pelvic floor function and improving the quality of women's life are the direction of our efforts in the future.

At present, common detection methods of PFM strength include digital palpation, vaginal balloon, and surface electromyography (SEMG) and so on. Digital palpation can quantify the PFM strength directly, although it has always been questioned for its subjectivity. Vaginal balloon is more objective but not as precise as digital palpation. SEMG detects the electrical activity of PFM, yet its reliability in clinical application is still controversial. There is a strong correlation among the three methods in the assessment of the PFM strength [12-14]. Digital palpation is mainly used in the census, while SEMG is normally used in evaluation of therapeutic effect of the PFM strength [14]. In this study, through census of the PFM strength of women in postpartum 6-8 weeks, it can be known that the PFM strength of women having cesarean delivery is higher than that of women having vaginal delivery (including perineal laceration, episiotomy, and forceps assisted vaginal delivery), although $\mathrm{t}$ primiparas having cesarean delivery have older age, heavier baby's weight and higher rate of GDM than those having vaginal delivery. This shows vaginal delivery is one of the important factors causing PFM damage in recent postpartum, which is consistent with results of previous researches $[15,16]$. This study shows that the PFM strength of primiparas having perineal laceration vaginal delivery is higher than that of primiparas having episiotomy vaginal delivery or forceps assisted vaginal delivery, which is mainly due to that the episiotomy may damage PFM and the integrity of pudendal nerve. It has always been a controversial topic to perform routine episiotomy on low-risk pregnant women during vaginal 
delivery [17-19]. Supporters think that routine episiotomy can protect the anal sphincter [18]. Opponents argue that routine episiotomy can increase the rates of postpartum bleeding, postpartum perineal incision infection, postpartum pain, urinary morbidity, and so on [19]. Our study suggests that routine episiotomy cannot protect the PFM from being damaged. The PFM damage is also related with PFDs, therefore the effective measure to reduce and prevent PFDs on low-risk pregnant women is to protect the perineal integrity and do not perform routine episiotomy during vaginal delivery. Many studies show that operation vaginal delivery by forceps or vacuums significantly damage the PFM strength and increase the risk of PFDs during both the recent and long term postpartum period [20-22]. But our study shows that there is no significant difference between episiotomy and forceps assisted vaginal delivery. This may be due to that the rate of forceps assisted vaginal delivery is very low in China, which is $1.51 \%(72 / 4769)$ in our hospital of primiparous women; for comparison, the percentage of operative vaginal delivery is $29.1 \%$ among primigrous women in Ireland [23]. The fetal head position will be lower or outlet when using forceps, and some difficult forceps vaginal deliveries have been replaced by cesarean delivery in our hospital. Vaginal delivery is an independent risk factor leading to PFDs of primiparous women in short-time postpartum period. Although cesarean delivery reduces the risk of pelvic floor trauma, it is not entirely protective [24]. Cesarean delivery is a protective delivery method for PFM of women in recent postpartum, but may be not useful for women in late postpartum [17]. Moreover, cesarean delivery may easily bring other severe complications. Episiotomy may cause injury of PFM in low risk vaginal delivery or forceps vaginal delivery. We should try our best to reduce the rate of episiotomy in order to protect PFM in primiparous women.

When the damage of PFM occurs, how to restore and exercise the weak PFM in the short-time postpartum period is the focus. Many studies show that the PFM training can prevent and treat pelvic floor disease in antenatal and postnatal women [25]. Our study shows that the combined treatment of at-home PFM exercise plus in-hospital electrical stimulation combined with biofeedback is an effective way to restore the PFM strength that is damaged by pregnancy and delivery in a short-time.

\section{The limitation of our study}

Our study is subjected to a few limitations. Firstly, the modified Oxford score is very simple and is not sensitive enough to describe accurate change of PFM strength of the postpartum women. Another limitation is that palpation does not provide global assessment of the levator ani muscle which can be measured by techniques such as ultrasound imaging, MRI, a predefined protocol [26], and so on. Lastly, due to lack of experience, it is difficult for postpartum women to properly cooperate with examination expert.

The high rate of cesarean delivery and low rate of operative vaginal delivery are the limitations of our study. In China, the high cesarean delivery rate is a social problem, nearly half of all newborns in China are delivered by cesarean approach [27]. From January 2013 to January 2014, there were 13,490 cases of Chinese s primiparas delivered in our birth centre, the overall rate of cesarean delivery was $43.1 \%(5809 / 13490)$ and the overall rate of operative vaginal delivery was $1.6 \%(220 / 13490)$. Many operative vaginal deliveries were replaced by cesarean delivery, and the rate of maternal request cesarean delivery was nearly $10.0 \%(1351 / 13490)$. There was common preineum local block anesthesia before episiotomy but no neuraxial labor anlagesia for vaginal delivery.

\section{Conclusions}

Vaginal delivery is an independent risk factor causing the damage of PFM in the short-term after delivery. Episiotomy may cause injury of PFM. Through PFM training at home plus electrical stimulation combined with biofeedback therapy in hospital, those damage will resume as soon as possible in the short-time period after postpartum.

\section{Additional file}

Additional file 1: Individual patient data. (XLSX 304 kb)

\section{Abbreviations}

GDM: Gestational diabetes mellitus; PFDs: Pelvic floor disorders; PFM: Pelvic floor muscle; SEMG: Surface electromyography

\section{Acknowledgments}

Thank the postpartum women, students, midwives and nurses for their contribution to this study. Special thanks to Dr. Liyan Gong for the contributions to guide the PFM training at home and in hospital.

\section{Funding}

This work was supported by the Natural Science Foundation of Hubei Province, China (No.2009CDA064, No: 2011 CDC098) and Foundation from Health and Family Planning Commission of Hubei Province (No: WJ2015MB121).

Availability of data and materials

This study obtains the consent from the participants to report individual patient data (see in Additional file 1).

\section{Authors' contributions}

$Y Z$, who was the assessor of the PFM strength, conceived the study, analyzed the data, interpreted the results, and drafted the manuscript. MX conceived the study and drafted the manuscript. WT, who was also the assessor of the PFM strength, guided the PFM training and analyzed the data. $L Z, H N$, FQ analyzed the data and revised the manuscript. All authors read and approved the final manuscript.

\section{Ethics approval and consent to participate}

The study protocol was approved by the Ethics Committee of Maternal and Child Health Hospital of Hubei Province(201301) and all included women signed written informed consent.

Consent for publication

Not applicable. 


\section{Competing interests}

The authors declare that they have no competing interests.

\section{Publisher's Note}

Springer Nature remains neutral with regard to jurisdictional claims in published maps and institutional affiliations.

\section{Author details}

${ }^{1}$ Department of Obstetrics, Maternal and Child Health Hospital of Hubei Province, No 745 Wuluo Road, Wuhan City, People's Republic of China. ${ }^{2}$ Department of Obstetrics and Gynecology, Union Hospital of Tongji Medical College, Huazhong University of Science and Technology, Wuhan City, People's Republic of China. ${ }^{3}$ Department of Obstetrics and Gynecology, Tongji Hospital of Tongji Medical College, Huazhong University of Science and Technology, Wuhan City, People's Republic of China.

Received: 29 December 2017 Accepted: 25 June 2018

Published online: 03 July 2018

\section{References}

1. Jelovsek JE, Barber MD. Women seeking treatment for advanced pelvic organ prolapse have decreased body image and quality of life. Am J Obstet Gynecol. 2006;194(5):1455-61. PMID: 16647928

2. van Veelen GA, Schweitzer KJ, van der Vaart $\mathrm{CH}$. Ultrasound imaging of the pelvic floor: changes in anatomy during and after first pregnancy. Ultrasound Obstet Gynecol. 2014;44(1):476-80. PMID: 24436146

3. Herrmann V, Scarpa K, Palma PC, Riccetto CZ. Stress urinary incontinence 3 years after pregnancy: correlation to mode of delivery and parity. Int Urogynecol J Pelvic Floor Dysfunct. 2009;20(3):281-8. PMID: 19020787

4. Tennfjord MK, Hilde G, Stær-Jensen J, Ellström Engh M, Bø K. Dyspareunia and pelvic floor muscle function before and during pregnancy and after childbirth. Int Urogynecol J. 2014;25(9):1227-35. PMID: 24687365

5. Chen X, Gong Y, Wu D, Li X, Li H, Tong X, et al. Pre- and postoperative evaluation of pelvic floor muscle function in POP patients using surface electromyography and digital palpation. Neurourol Urodyn. 2014;33(4): 403-7. PMID: 23754311

6. Zhao Y, Xiao M, Tang F, Tang W, Yin H, Sun GQ, et al. The effect of water immersion delivery on the strength of pelvic floor muscle and pelvic floor disorders during postpartum period: an experimental study. Medicine (Baltimore). 2017:96(41):e8124. PMID:29019880

7. Lee IS, Choi ES. Pelvic floor muscle exercise by biofeedback and electrical stimulation to reinforce the pelvic floor muscle after normal delivery. Taehan Kanho Hakhoe Chi. 2006:36(8):1374-80. PMID: 17215611

8. Yang S, Sang W, Feng J, Zhao H, Li X, Li P, et al. The effect of rehabilitation exercises combined with direct vagina low voltage low frequencyelectric stimulation on pelvic nerve electrophysiology and tissue function in primiparouswomen: a randomised controlled trial. J Clin Nurs. 2017;26(23-24):4537-47. PMID: 28252827

9. Shek K, Dietz H. Intrapartum risk factors of levator trauma. Br J Obstet Gynecol. 2010;117(12):1485-92. PMID: 20735379

10. Glazener CM, MacArthur C, Hagen S, Elders A, Lancashire R, Herbison GP, et al. Twelve-year follow-up of conservative management of postnatal urinary and faecal incontinence and prolapse outcomes: randomized controlled trial. BJOG. 2014;121(1):112-20. PMID: 24148807

11. Boyle R, Hay-Smith EJ, Cody JD, Mørkved S. Pelvic floor muscle training for prevention and treatment of urinary and faecal incontinence in antenatal and postnatal women. Cochrane Database Syst Rev. 2012;17(10):CD007471. PMID: 23076935

12. Peng $Y$, Miller BD, Boone TB, Zhang Y. Modern theories of pelvic floor support: a topical review of modern studies on structural and functional pelvic floor support from medical imaging, computational modeling, and electromyographic perspectives. Curr Urol Rep. 2018;19(1):9. PMID 29435856

13. Botelho S, Pereira LC, Marques J, et al. Is there correlation between electromyography and digital palpation as means of measuring pelvic floor muscle contractility in nulliparous, pregnant, and postpartum women? Neurourol Urodyn. 2012;32(5):420-3. PMID: 23023961

14. Riesco ML, Caroci Ade S, de Oliveira SM, Lopes MH. Perineal muscle strength during pregnancy and postpartum: the correlation between perineometry and digital vaginal palpation. Rev Lat Am Enfermagem. 2010; 18(6):1138-44. PMID: 21340279
15. Memon $\mathrm{H}$, Handa VL. Pelvic floor disorders following vaginal or cecarean delivery. Curr Opin Obstet Gynecol. 2012;24(5):349-54. PMID: 22907482

16. Lavy Y, Sand PK, Kaniel Cl, Hochner-Celnikier D. Can pelvic floor injury secondary to delivery be prevented? Int Urogynecol J. 2012;23(2):165-73. PMID: 21822710

17. Handa VL, Blomquist JL, McDermott KC, Friedman S, Muñoz A. Pelvic floor disorders after vaginal birth: effect of episiotomy, perineal laceration, and operative birth. Obstet Gynecol. 2012;119(2 Pt 1):233-9. PMID: 22227639

18. Heit M, Mudd K, Culligan P. Prevention of childbirth injuries to the pelvic floor. Curr Womens Health Rep. 2001;1(1):72-80. PMID: 12112955

19. Macleod M, Goyder K, Howarth L, Bahl R, Strachan B, Murphy DJ. Morbidity experienced by women before and after operative vaginal delivery: prospective cohort study nested within a two-centre randomized controlled trial of restrictive versus routine use of episiotomy. BJOG. 2013; 120(8):1020-6. PMID: 23464382

20. Barbosa Am MG, Piculo F, Rudge CV, Calderon IM, Rudge MV. Prevalence of urinary incontinence and pelvic floor muscle dysfunction in primiparas two years after cesarean section:cross-sectional study. Sao Paulo Med J. 2013; 131(2):95-9. PMID: 23657511

21. Friedman S, Blomquist JL, Nugent JM, McDermott KC, Muñoz A, Handa VL. Pelvic muscle strength after childbirth. Obstet Gynecol. 2012;120(5):1021-8. PMID: 23090518

22. Handa VL, Blomquist JL, Knoepp LR, Hoskey KA, McDermott KC, Muñoz A. Pelvic floor disorders 5-10 years after vaginal or cesarean childbirth. Obstet Gynecol. 2011;118(4):777-84. PMID: 21897313

23. Daly N, Bonham S, O'Dwyer V, O'Connor C, Kent E, Turner MJ. National variations in operative vaginal deliveries in Ireland. Int J Gynaecol Obstet. 2014;125(3):210-3. PMID: 24709535

24. Elenskaia K, Thakar R, Sultan AH, Scheer I, Beggs A. The effect of pregnancy and childbirth on pelvic floor muscle function. Int Urogynecol J. 2011;22(11): 1421-7. PMID: 21789660

25. Xing W, Zhang Y, Gu C, Lizarondo L. Pelvic floor muscle training for the prevention of urinary incontinence in antenatal and postnatal women: a best practice implementation project. JBI Database System Rev Implement Rep. 2017:15(2):567-83. PMID:28178026

26. Kruger JA, Budgett SC, Wong V, Nielsen PMF, Nash MP, Smalldridge J, et al. Characterizing levator-ani muscle stiffness pre- and post-childbirth in European and Polynesian women in New Zealand: a pilot study. Acta Obstet Gynecol Scand. 2017:96(10):1234-42. PMID:28664535

27. Xiong C, Zhou A, Cao Z, Zhang Y, Qiu L, Yao C, et al. Association of prepregnancy body mass index, gestational weight gain with cesarean secti on in termdeliveries of China. Sci Rep. 2016;6:37168. PMID 27872480

\section{Ready to submit your research? Choose BMC and benefit from:}

- fast, convenient online submission

- thorough peer review by experienced researchers in your field

- rapid publication on acceptance

- support for research data, including large and complex data types

- gold Open Access which fosters wider collaboration and increased citations

- maximum visibility for your research: over $100 \mathrm{M}$ website views per year

At BMC, research is always in progress.

Learn more biomedcentral.com/submissions 